\title{
A physiological measure of shifting connections in the Rana pipiens retinotectal system
}

\author{
SCOTT E. FRASER \\ Department of Physiology and Biophysics, University of California, Irvine, \\ California 92717, USA \\ AND R. KEVIN HUNT* \\ Thomas C. Jenkins Department of Biophysics, The Johns Hopkins University, \\ Baltimore, Maryland 21218, USA
}

\section{SUMMARY}

The retinotectal connections of developing Rana tadpoles and froglets have been studied using light-pipe techniques to directly assay the pattern of the projection from the retina to the tectum. The projection site of the retina surrounding the optic nerve head was determined at two different stages of development (late larval and metamorphic frog) on the same animal. Small electrolytic marker lesions were used to mark the tectal sites to which the optic nerve head projected at these two times. Comparison of the positions of the two lesions gives a direct measure of the shift in the projection during the interlesion time interval of one week. The results indicate a shift in the projection of $275 \mu \mathrm{m} \mathrm{week}^{-1}$ in late larval life. Previous work in Xenopus using the light-pipe techniques indicated a qualitatively similar shift during equivalent stages of development, but significantly smaller in magnitude. In the present study, topographic postsynaptic units could be recorded at all stages investigated, indicating functional synapses between the optic nerve fibres and the tectum. Thus, these studies offer evidence of a significant shift in the functional connection pattern of the amphibian retinotectal map during development, in agreement with the recent anatomical data from other laboratories on the Rana and goldfish visual system.

\section{INTRODUCTION}

The lower vertebrate visual system has been a focus of numerous studies on both the specificity and plasticity of neuronal connections (see reviews: Fraser \& Hunt, $1980 a$; Meyer, 1982). The popularity of this system stems from (i) the simple projection pattern from each eye to the contralateral optic tectum that characterizes the retinotectal projection, and (ii) the availability of straightforward assays for the topography of the projection. Experiments have addressed the specificity of the connection pattern between the eye and the brain in several ways. For example, the cells of the eyebud have been shown to possess some positional information by experiments in which fragments of a donor eyebud were grafted to

\footnotetext{
* Present address: The Salk Institute for Biological Studies, P.O. Box 85800, San Diego, CA 92138, USA.
}

Key words: Rana pipiens, retinotectal system, connections, projection nerve fibre, visual system, synapse. 
ectopic sites in a host eyebud (cf. Conway, Feiock \& Hunt, 1980; Cooke \& Gaze, 1983), or in which portions of the eyebud were labelled to permit the optic nerve fibres from that region to be followed (Holt \& Harris, 1983; Holt, 1984). In both settings, the optic nerve fibres from the fragment of eyebud can terminate in the tectum at the 'correct' region for their position of origin in the eyebud. The retinotectal system has also provided a wealth of interesting and valuable data on the plasticity of connections in experimentally perturbed situations. For example, small groups of nerve fibres can expand their projection to fill more than their appropriate portion of a denervated optic tectum (cf. Meyer, 1978; Fraser \& Hunt, 1980b). While it is clear that the significant specificity in the system could help pattern the projection, it is perhaps less obvious that there should be the need for a large degree of plasticity in the normal development of the retinotectal projection.

The possibility that plasticity plays a major role in the normal development of the retinotectal projection was first considered in the Sliding Connections Hypothesis of Gaze and his coworkers (Gaze, Chung \& Keating, 1972; Gaze, Keating, Ostberg \& Chung, 1979; Chung, 1974). This proposal was based upon the observation that in Xenopus the retina and the tectum maintain a topographic retinotectal projection while they both continue to grow (Gaze et al. 1972), even though the growth patterns of the retina and the tectum are quite different. The retina grows by adding concentric rings of cells to its rim (the ciliary margin), whereas the tectum grows by adding wedges of cells at its posterior/medial boundary (Straznicky \& Gaze, 1971, 1972; Jacobson, 1976). Thus, it was proposed that the synaptic relationships between optic nerve fibres and tectal cells do not remain static but instead shift continuously to compensate for the mismatch of the growth patterns. Studies of the histogenesis of the eye and tectum of other lower vertebrates have demonstrated similar mismatched patterns of growth, suggesting that sliding connections may be present in a variety of lower vertebrates including frogs and goldfish (see reviews: Meyer, 1982; Easter, 1983).

Anatomical and physiological studies of the Xenopus visual system provided the original supportive evidence of sliding connections during the development of the retinotectal projection. The anatomical data centred on a double-label autoradiographic technique in which newly added cells in the tectum were marked with $\left[{ }^{3} \mathrm{H}\right]$ thymidine and the optic nerve fibres were marked with $\left[{ }^{3} \mathrm{H}\right]$ proline. With increasing survival times after the concurrent isotope injections, the labelled optic nerve fibres were found to move with respect to the labelled tectal cells (Scott \& Lazar, 1976). This same anatomical technique has been used in another laboratory, yielding contrary results (Jacobson, 1977). More recent experiments have strengthened the evidence of Scott \& Lazar (1976) and provided additional controls for the techniques (Gaze et al. 1979). Furthermore, anatomical work in other species based on the transport of Horseradish Peroxidase (HRP) has further strengthened the anatomical data and demonstrated single-cell anatomy consistent with the proposed shift in the map during development (Easter \& Stuermer, 1984; Reh \& Constantine-Paton, 1984; Cook, Rankin \& Stevens, 1983). 
Physiological evidence of the shift in the retinotectal map would provide an independent confirmation of the anatomical data, but most attempts have not successfully addressed the problem. Early electrophysiological studies of sliding connections in Xenopus examined the visual field projections to the tectum at successive stages of larval development. Stimuli were presented to the animal to determine the regions of visual field that project to electrode positions in the tectum. These visuotectal maps demonstrated distortions and changes consistent with the hypothesis; however, the retina undergoes asymmetric growth during the developmental periods investigated (Jacobson, 1976; Beach \& Jacobson, 1979). This asymmetry in growth pattern must lead to a displacement of the optic disc and the oldest retina around it with respect to both the external landmarks of the eye and the visual field boundaries. Thus, there is a change in the relationship between visual stimuli and their positions in the retina during the very developmental stages at which the physiological experiments on sliding connections were performed. We were able to circumvent this difficulty by the use of light-pipe recording techniques to directly assay the pattern of the retinotectal projection in Xenopus (Fraser, 1980a, 1983a). A small marker-lesion was made at the site of the projection from a defined position in the retina at two times in the same animal, yielding a direct physiological assay of the shift in the Xenopus retinotectal projection (Fraser, 1980a, 1983a). These newer methods detected a small but reliable shift in the tectal projection site of the optic nerve head during metamorphic climax, and confirmed that the changes observed in previous studies were due in part to a shift in the pattern of the retinotectal projection.

Here, we extend the previous experiments on Xenopus by turning to another species of frog, Rana pipiens. The experiments on Xenopus used electrophysiological techniques to record from the presynaptic terminals of the optic nerve fibres, sacrificing any information on the pattern of functional connections to the tectum. Isolating confirmed postsynaptic responses from tectal cells was too difficult in Xenopus juveniles and larvae to be used as an assay of the pattern of the retinotectal connections. In Rana, electrophysiological recording from tectal cells permitted the connectivity of the retinotectal map to be directly determined. Furthermore, the size of the tectum and the growth patterns of the retina and tectum in Rana should increase the magnitude of the shift in the retinotectal projection. The results of the present set of experiments indicate that the functional pattern of the connections between the retina and tectum shift at a rate of about $275 \mu \mathrm{m}$ week $^{-1}$ during late larval stages of Rana development.

\section{MATERIALS AND METHODS}

\section{Experimental design}

The experimental design was an extension of the earlier light-pipe experiments in Xenopus (Fraser, 1983a), using the techniques described below. The projection site of the retina surrounding the optic nerve head on the tectum was determined, using the light-pipe techniques, and a small marker lesion was made at the site. The animal was revived and reared for an additional week, at which time the optic nerve head projection site was again determined and 
marked. Following histological processing of the brain, the positions of the marker lesions were compared and any disparity served as a measure of the amount of shift in the projection during the interlesion time period.

\section{Animals}

Rana pipiens spawnings were obtained from a commercial supplier and were reared in clear plastic trays until the time of the experiment. The animals were then transferred to clear glass bowls and individually reared. The animals were grown at $22^{\circ} \mathrm{C}$ in an artificial pond water (rearing solution: 15\% Holtfreter's solution, 5\% Steinberg's solution), and were fed boiled romaine lettuce daily. For an experiment, the animals were anaesthetized in methyl sulphonate (Finquel, Ayerst) and were paralysed with d-tubocurarine (Lilly). The skin overlying the skull was deflected, making sure that the cut edges were far from the region of the tectum. The skull was then cut on three sides around the tectum and deflected to allow access to the dorsal surface of the optic tectum. The animal was wrapped in a moist towelette, mounted in the centre of a contoured styrofoam holder, and flushed periodically with fresh water during the mapping session. Following the experiment, the skull and skin were folded back into place and allowed to dry slightly to help secure them. The animals were revived on moist paper towelling and then maintained in rearing solution supplemented with gentamycin sulphate (Sigma, $50 \mu \mathrm{g} \mathrm{ml}^{-1}$ final concentration).

\section{Electrophysiology}

Conventional extracellular electrophysiology was used to record the pattern of the retinotectal projection (multi-unit recording) and to assay for the connectivity of the projection (single-unit recording). Platinum-tipped platinum-iridium electrodes were used for all recording (resistance before tipping: 4Mohm; after tipping: 1-2 Mohm). The signals from the electrode were amplified $(\times 1000)$ and filtered $(100 \mathrm{~Hz}-10 \mathrm{kHz}$ bandpass, $60 \mathrm{~Hz}$ rejection) before being displayed on an oscilloscope and played over a loudspeaker.

To record from the optic nerve terminal arbors, the electrode was lowered into the superficial neuropil of the left optic tectum. A light stimulus from an Aimark projection perimeter, centred on the animal's right eye, was used to explore the visual field of that eye. When a response was obtained, a record of the stimulus position was made on the perimeter's punch chart. For typical mapping of the projection, this procedure was repeated in a lattice of electrode positions. When searching for the termination site of a particular location in the visual field, the electrode position was interpolated between previous penetrations. Using this successive interpolation technique, the termination site of a particular locus could be determined in fewer than six electrode penetrations.

Single-unit recording was used to identify postsynaptic responses in the tectum. The electrode was lowered deeper into the tectum and a hydraulic microdrive was used to 'tune' a single unit. Single units were identified on the basis of their amplitude with the help of a amplitude discriminator, and the constancy of their waveform observed on a storage oscilloscope. Occasionally, a waveform averager (Ortec) was used to help in the isolation of single units. Once a single unit was isolated, it was taken as postsynaptic if it met two of the following criteria: (1) large receptive field, (2) responses that were easily fatigued, (3) complex receptive field properties (i.e. direction sensitive). Occasionally, multimodal response characteristics (visual and somatosensory) were also used as a screen for postsynaptic tectal responses. Because artifacts due to movement of the animals during somatosensory stimulation might produce false positive results, this criterion was used less often.

\section{Light-pipe recording}

Light-pipe recording is a means of placing a photosensitive device in the retina of the animal in order to measure the correspondence between loci in the visual field of the animal and landmarks in the retina. When used in conjunction with the more conventional extracellular electrophysiological assay of the visuotectal map, the projection site on the tectum of a particular retinal locus may be determined. The retinal landmark for these studies was the optic 
nerve head, chosen because it is reliably positioned and can be unambiguously identified. The visual field landmark was the optical axis of the eye, defined as the line perpendicular to the centre of the cornea. It was determined by reflecting a small light (held next to the observer's eye) off of the frog's cornea. When the reflection was centred on the pupil of the eye, the point midway between the light and the observer's eye defined the optical axis of the eye. This position was marked on the record chart of the projection perimeter for later reference. The optical axis determined in this way depends only on the air-cornea interface, and therefore may differ slightly from the true optical axis that might be determined if all the optical properties of the eye were taken into account. This possible difference does not affect the present study since the optical axis is used only as a convenient, reproducible and non-invasive point of reference.

A short segment of pulled glass rod (tip size 2-10 $\mu \mathrm{m}$ ) with a photodarlington sealed to the back was inserted through the back of the eye at the optic nerve head using a micromanipulator. Because of its small tip size, the glass probe could be inserted through the supporting layers of the eye and into the photoreceptor layer without distorting the shape of the eye or altering the response properties of eye recorded in the tectum. The eye was deflected after severing some of the ocular muscles in order to allow better access to the optic nerve. Light, striking the tip of the glass rod was conveyed back to the photodarlington and caused a photocurrent that was monitored on an oscilloscope. The visual field of the eye was searched with a light source (Aimark perimeter or a light held against the perimeter) until the locus that caused a photocurrent was found. The region of visual field within which a spot of light could excite the photodarlington was always several degrees in diameter, but a very small region (less than $2^{\circ}$ ) produced the maximum response. The region of maximal response was recorded on the projection perimeter record chart, using the optical axis of the eye as a reference. In order to establish the accuracy of this in situ determination of the position of the optic nerve head, the measurement was repeated on isolated eyes. An eye was dissected free from the animal with iridectomy scissors and mounted at the centre of the projection perimeter. The eye holder was made from a small piece of opaque plastic sheeting $(2 \mathrm{~cm} \times 2 \mathrm{~cm} \times 1 \mathrm{~mm})$ with a central hole about $0.5 \mathrm{~mm}$ larger than the diameter of the eye. A small drop of water was placed between the eye and the plastic. The water spread to form an annulus between the eye and the plastic and held the eye in place by surface tension, causing very little, if any, distortion of the eye. Both the optic axis of the eye and the position of the optic nerve head were determined for the isolated eye, and their correspondence was found to agree with that recorded in situ to well within $5^{\circ}$. Based on these measurements and determinations of the uncertainties inherent in the technique (by repeated measurements on the same animal), we estimate the overall accuracy of the lightpipe techniques to be better than $5^{\circ}$.

\section{Histology and marker lesions}

Electrode positions were recorded by making a small electrolytic marker lesion in the tectum. The electrode was lowered into the deeper layers of the tectum, and a D.C. current source was used to pass $5 \mu \mathrm{amp}$ through the electrode (electrode negative) for 10 to $20 \mathrm{~s}$. These lesions produce a small amount of damage at the electrode tip and along the electrode track, that persists for at least one week. Following the termination of the second experiment, the animals were heavily anaesthetized in MS-222 and were fixed in Bouin's fixative. The heads of the animals were later embedded in paraplast, sectioned at $10 \mu \mathrm{m}$ and stained by the picro-panceau method (Humason, 1979). The sections were then scanned for the lesions and tracings were made of the sections of interest with the aid of a television camera. No compensation for shrinkage during processing was made; therefore, the measurement of the movement of the optic nerve head projection is probably an underestimate.

\section{RESULTS}

The experimental approach consisted of two phases: (1) to determine the correspondence between the optic nerve head and the optical axis of the eye, and 
(2) to use this knowledge to mark the termination site in the tectum of the optic nerve head at two different developmental stages in the same animal.

\section{Optic nerve head position}

Light-pipe recording was used to measure the position of the optic nerve head in the visual field of the frog eye at various stages. All measurements were made with respect to the optical axis of the eye, determined by centring a reflected spot of light on the cornea (see Materials and Methods section). The light pipe was inserted through the back of the eye at the optic nerve head and the position of the optic nerve head in the visual field of the eye was determined. Animals ranging from larval stage $\mathrm{XV}$ to newly metamorphosed frogs were tested (Taylor \& Kollros stages used throughout; $n=4-6$ for each stage); in all cases the optic nerve head was found to be well within $5^{\circ}$ of the optical axis of the eye. Thus, the large deviations of the optic nerve head seen previously in Xenopus (Fraser, 1983a) do not appear to occur in Rana, consistent with the symmetrical growth pattern of the Rana eye. Caution should be exercised in generalizing this result however, because in our previous study of Xenopus, large differences of the optic nerve head's position in the eye were found between groups of animals raised in different manners (e.g. different feeding regimens). Nevertheless, for all the groups of animals used in the present study, our experiments show that the optical axis of the eye was a good measure of the position of the optic nerve head.

\section{Electrophysiological mapping}

The order of the retinotectal projection and its connectivity were assayed in animals ranging from larval stage $\mathrm{XV}$ to a newly metamorphosed frog. The maps were quite orderly, even for relatively young tadpoles, showing distortions similar to those seen previously in Xenopus larvae, but less severe. The most noticeable defect in the maps of larvae were that they failed to cover the entire dorsal aspect of the tectum, leaving its medial and caudal portions largely denervated. This partial coverage is consistent with the autoradiographic data of others (Currie \& Cowan, 1975). By stage XX, the maps adopted an appearance very similar to the adult retinotectal map.

Fig. 1 shows the maps recorded from animals at stages XIX and XXV. At both stages the order of the map is normal, although the stage XIX map shows less complete coverage of the tectum. The size of the receptive fields (multi-unit receptive fields) was similar to that of metamorphic frogs: approximately $30^{\circ}$ at stage XIX and $25^{\circ}$ at stage XXV.

Comparison of the two maps shown in Fig. 1 suggests that the retinotectal projection is not static during the two weeks of growth between stages XIX and XXV. First, the coverage of the tectum by optic nerve fibres increases. Second, the tectum appears, in dorsal view, to have grown at least $150 \mu \mathrm{m}$ (although changes in the shape of the tectum might mask some of the growth or give the false impression of growth). Third, the projection site of the retina surrounding the 
optic nerve head has moved at least $150 \mu \mathrm{m}$ closer to the medial boundary of the tectum. Since growth of the tectum is from the caudomedial boundary, we can obtain an estimate of the movement of the central portion of the retina by summing the growth and movement distances. This yields a lower estimate of $300 \mu \mathrm{m}$ for the movement of the projection in the mediolateral dimension; this approach does not give any insight into the anteroposterior movement of the

A

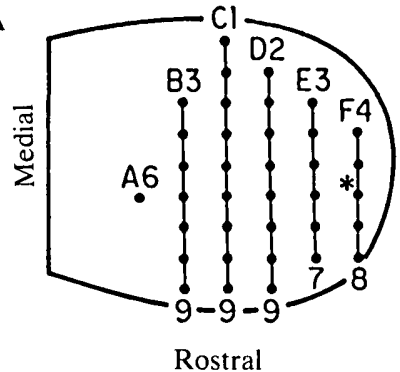

Left tectum

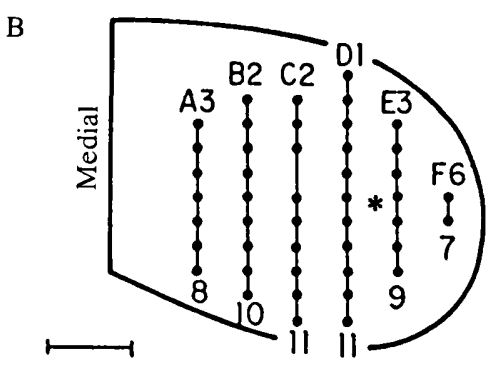

Rostral

Left tectum

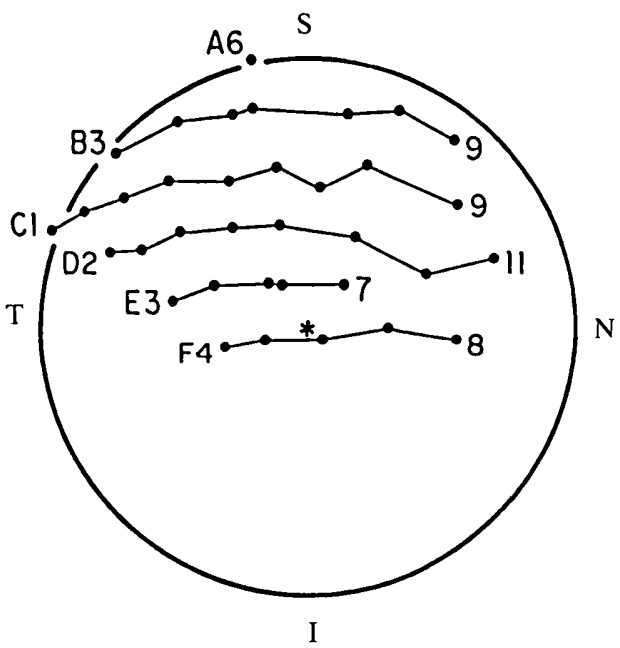

Right eye visual field

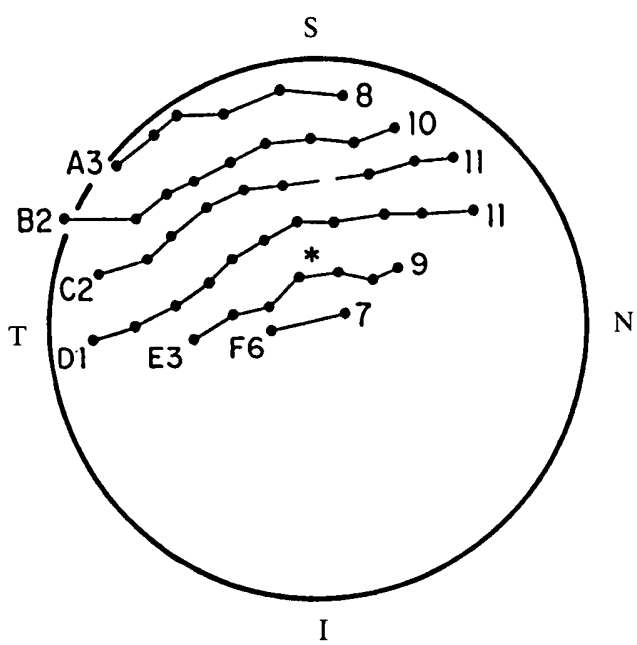

Right eye visual field

Fig. 1. Visuotectal maps of (A) stage XIX and (B) stage XXV Rana. The tectal outlines, drawn to scale from photographs of the experimental animals, demonstrate a change in the size and shape of the tectum between these two stages. The electrode was lowered into the tectal neuropil at each of the marked locations on the tectal outlines, and responses were recorded from optic nerve fibre terminals. The electrode positions are coded by a letter and number combination as shown. The centre of the responsive areas for that electrode position are marked by the dot in the chart of visual field. The position of the optic axis in visual field, determined as described in Materials and Methods by reflecting a spot of light off of the cornea, is marked by an asterisk. The projection site of this visual field position on the tectum is marked by an asterisk on the tectal outline. Scale bar, $400 \mu \mathrm{m}$. 
projection. However, such arguments can only provide a rough measure of the shift in the projection because of the assumptions that they require.

The electrical signals recorded in the typical electrophysiology experiment are thought to originate from the terminal arbors of the optic nerve fibres. Thus, maps such as those in Fig. 1 represent the ordering of the presynaptic terminals but offer little information as to the connections made to the tectum. In several animals from stage XIX to XXV, the presynaptic mapping was augmented with postsynaptic recording to demonstrate the connectivity pattern of the retinotectal projection. In total, more than 50 confirmed postsynaptic units (meeting the criteria outlined in the Materials and Methods section) in the central part of the retinotectal map were isolated in eleven animals. The receptive field sizes of these single units ranged from $20^{\circ}$ to $60^{\circ}$, and were noticeably larger than the single-unit receptive fields recorded from optic nerve terminals. In all cases the single-unit analysis showed that the central region of the projection was connected to postsynaptic cells as predicted from the presynaptic map. No systematic offset between the presynaptic and postsynaptic units was observed. This demonstrates that: (1) the optic nerve terminals responsible for the presynaptic responses in Fig. 1 form functional connections to the tectum, and (2) the retinotectal connection pattern is likely to strongly parallel the retinotectal projection pattern recorded in Fig. 1.

\section{Double-lesion experiment}

In order to assay for a shift in the retinotectal projection during late larval development in Rana, a double-lesion paradigm (Fraser, 1983a) was used. At two stages (separated by one week) in the development of individual larvae, the projection site on the tectum of the ganglion cells surrounding the optic nerve head was determined. The data presented above (see 'Optic nerve head position') indicate that the optic nerve head lies on the optical axis of the eye; therefore, the projection site of the optical axis was taken as the projection site of the retina surrounding the optic nerve head. This assumption considerably sped the assay, thereby reducing the trauma to the animal and increasing the survival rate. For each determination, a small electrolytic lesion was made to mark the tectal position. The animal was sacrificed shortly after the second lesion. Comparison of the two marker lesions then offered an assay of the amount of shift in the retinotectal map during the one-week interlesion time interval. In control experiments during the development of the double-lesion method in Xenopus (Fraser, $1980 a, 1983 a$ ), two determinations were separated by only a few hours and the lesions reliably superimposed to appear as one, slightly enlarged lesion. Control experiments on Rana showed that the alignment and localization of the tectal position was reliable to better than $5^{\circ}$. Thus, any disparity between the lesion positions greater than $50 \mu \mathrm{m}$ (the calculated maximum uncertainty) must reflect a rearrangement of the retinotectal projection.

Forty-six Rana pipiens were subjected to the double-lesion protocol, of which 23 survived and 10 had two recognizable lesions. For the remaining animals either 
A

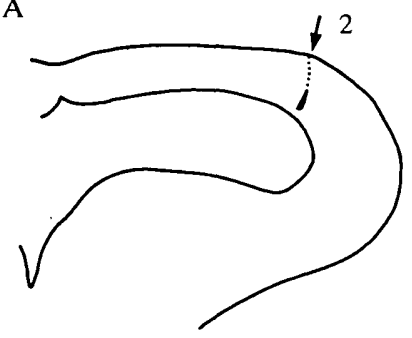

$\uparrow 11$ sections

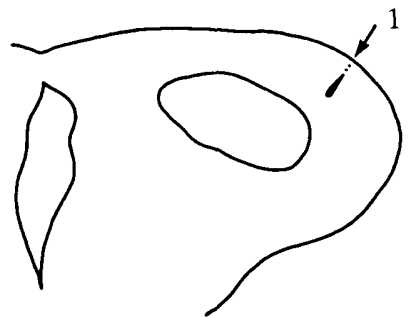

B

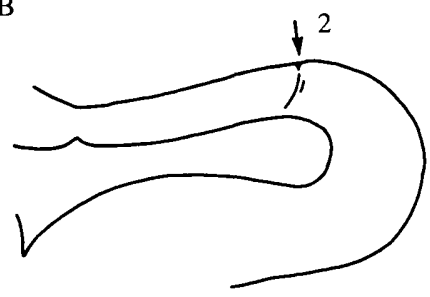

$\uparrow 9$ sections

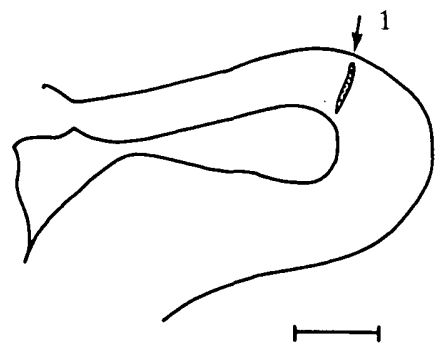

Fig. 2. Outlines of tectal sections from two different double-lesion animals. The first (stage XIX, bottom outlines) and second (stage XXI, top outlines) lesions were found in different sections, indicating a different rostrocaudal position. By counting the number of $10 \mu \mathrm{m}$ sections between the lesions, the projection of the retina around the optic nerve head appears to have moved caudally by $120 \mu \mathrm{m}$ in (A) and $100 \mu \mathrm{m}$ in (B). Furthermore, the distance from the midline of the tectum to the two lesions was different, indicating that the projection from the central retina shifted medially and caudally by $305 \mu \mathrm{m}$ (A) and $315 \mu \mathrm{m}$ (B) over the one-week interlesion time period.

Scale bar, $400 \mu \mathrm{m}$.

one of the lesions was not clearly identifiable or some of the sections of the tectum were lost or destroyed, making exact measurements impossible. In all cases, the second lesion was found to be medial and posterior to the first lesion, indicating a shift of the projection in the direction originally proposed by Gaze and his coworkers. The largest group of animals (6 cases) spanned the period of development from stage XIX to stage XXI, and demonstrated a shift in the projection of $275 \pm 50 \mu \mathrm{m}$ per week (mean \pm s.D.). Tracings from cross sections of the tecta of two experimental animals appear in Fig. 2A,B, and demonstrate a shift in the projection site of $305 \mu \mathrm{m}$ and $315 \mu \mathrm{m}$, respectively. The data for the remaining animals (ranging from stages XVIII to XXIV) demonstrated a similar caudomedial displacement in all cases (greater than $200 \mu$ m week $^{-1}$ ).

\section{DISCUSSION}

The results presented above offer physiological evidence that the retinotectal projection shifts during the development of Rana. The projection site in the tectum of the retina surrounding the optic nerve head was determined twice in the 
same animal at stages separated by one week. In all cases, the projection sites, marked by small electrolytic lesions, were found to be separated by more than $200 \mu \mathrm{m}$. The shift measured from stages XIX to XXI was $275 \pm 50 \mu \mathrm{m}^{\text {week }}{ }^{-1}$ (mean \pm S.D.), corresponding to roughly 10 to $15 \%$ of the tectal width per week. Reh \& Constantine-Paton (1984) have used localized Horseradish Peroxidase application to anatomically trace the termination of the optic nerve in Rana tadpoles of various ages; their data indicate a similar rate of shift. Thus, two different experimental approaches, each with different strengths and assumptions, both indicate the presence of sliding connections in the retinotectal projection of Rana as originally proposed in the sliding connections hypothesis of Gaze and coworkers $(1972,1979$; Chung, 1974). It therefore seems likely that the wealth of data on experimentally induced plasticity in the retinotectal system of lower vertebrates reflects a feature of the normal development of the system.

The rate of shift observed in the present study is double or triple the rate measured by the same techniques in Xenopus $(150 \mu \mathrm{m}$ or $15 \%$ of the tectal width in two weeks). This increased rate of shift probably reflects: (1) the larger size of the Rana visual system, (2) the lack of asymmetric retinal growth, and (3) the delayed coverage of the entire tectum by the innervating optic nerve fibres. The asymmetric growth of the Xenopus retina appears to reduce the required shift in the projection, by partially reducing the growth pattern mismatch between the eye and the tectum (Jacobson, 1976; Fraser, 1983a). Simple calculations show that the asymmetric growth of the Xenopus retina reduces the shift in the optic nerve terminals approximately $50 \%$ from that required if the retina grew symmetrically as in Rana (Fraser, 1983a). While tectal histogenesis in Rana slows somewhat near metamorphosis, the rapid growth of the tectum during early and midlarval stages results in a region of tectum at the caudomedial border that is not innervated until late larval stages (see Fig. 1A; see also Currie \& Cowan, 1975). This effectively prolongs the effects of the growth mismatch on the projection pattern until the time of the metamorphic climax, when the entire tectum is finally innervated.

Previous studies on Xenopus, ranging from anatomical double-label autoradiography experiments to physiological visuotectal and retinotectal mapping experiments (Gaze, Keating \& Chung, 1974; Gaze et al. 1979; Fraser, 1983a), indicated that the retinotectal projection shifts during development. These previous studies were all limited in that the shifting of the presynaptic terminals was determined; hence, any shifting in the connection patterns could only be inferred from the data. Postsynaptic single-unit recording in Xenopus tadpoles could not yield enough data to convincingly demonstrate a shift in the connection pattern (Fraser, unpublished). Laminar field potential studies have shown that optic nerve connections to the tectum are present at the stages investigated (Gaze et al. 1974) but cannot offer information as to the pattern of the connections that produce the observed field potentials. Electron microscopic studies demonstrated the presence of mature synapses as well as developing and degenerating synapses, consistent with the idea of changing synaptic relationships, but again short of definitive evidence. 
In the present study postsynaptic single-unit recording was used to confirm that optic nerve terminals from the central region of the retina were forming functional connections to the tectum during the period that the shift in the projection was taking place. This evidence makes it more likely that the measured shift in the retinotectal projection is accompanied by a similar shift in the connection pattern. In Xenopus the rather modest shift in the projection pattern observed over two weeks of late larval development (Fraser, 1983a) could conceivably have resulted solely from selective 'pruning' of arbor branches. This could lead to a shift in the extracellularly recorded signals without the formation of new synapses. The present results, however, make this argument less tenable in Rana by demonstrating both a much larger shift in the projection, and the formation of functional topographic connections by optic nerve terminals in the tectum. Thus, it appears that the retinotectal map reflects a steady state that appears outwardly constant on a large scale despite underlying dynamic rearrangements, in which synapses are continually sprouting and retracting, as has been proposed in this and other systems (cf. von der Malsburg \& Willshaw, 1977; Van Essen, 1982). Dynamic rearrangements of this type have recently been directly observed in the anteroposterior ordering of the retinotectal projection of young Xenopus larvae (Fraser \& O'Rourke, 1985; O'Rourke \& Fraser, 1986).

The dynamic nature of the retinotectal projection and the shift in the overall pattern that occurs with age argues strongly against a strict recognition of 'target sites' in the tectum as the sole mechanism producing the ordering of the retinotectal map. However, the results should not be interpreted as evidence for a lack of either best-fit target sites on the tectum or the molecular labels that might subserve them. Two lines of evidence from other studies highlight this issue. First, the data of Holt \& Harris (1983) on the ordering of the initial retinotectal map are best explained by the presence of target affinities that help to guide the developing optic nerve fibres to their correct 'targets' in the tectum. Additional experiments demonstrate that this role cannot be filled by differential fibre arrival times or by the position of fibre ingrowth (Holt, 1984). Second, the results of computer modelling studies indicate that plasticity and best-fit targets on the tectum are not mutually exclusive. Two different models of nerve patterning in the retinotectal system (Fraser, 1980b, 1985; Whitelaw \& Cowan, 1982) use target affinities to help in ordering the retinotectal connections, yet demonstrate considerable plasticity. While both models relegate target-specific affinities to a more minor role, if these affinities are totally eliminated, large blocks of data can no longer be simulated. Thus, both theoretical and experimental evidence suggest that target affinities assist in the development of the retinotectal map; furthermore, the theoretical investigations demonstrate that plasticity and target affinities are not mutually exclusive concepts. The data presented in this paper are consistent with the view that target affinities exist on the tectum but may be over-ridden or even altered during development to preserve a topographically ordered pattern of connections between a growing retina and tectum. 
We thank Marija Duda for assistance with the histology in portions of this study, and Drs M. Bronner-Fraser, N. O'Rourke and J. Schmidt for their comments on the manuscript. Supported by grants from NIH (NS14807 to R.K.H.) and from NSF (BNS 8023638 to S.E.F.). A preliminary report of some of this work has appeared (Fraser, 1983b).

\section{REFERENCES}

BEACH, D. H. \& JACOBSON, M. (1979). Patterns of cell proliferation in the retina of the clawed frog during development. J. comp. Neurol. 183, 603-614.

Chung, S.-H. (1974). In search of the rules for nerve connections. Cell 3, 201-205.

Conway, K., Feiock, K. \& Hunt, R. K. (1980). Polyclones and patterns in growing Xenopus eye. Curr. Top. devl Biol. 15, 217-317.

Cook, J. E., Rankin, E. C. C. \& Stevens, H. P. (1983). A pattern of optic axons in the normal goldfish consistent with the caudal migration of optic terminals during development. Expl Brain Res. 52, 147-151.

COOKE, J. \& GAZE, R. M. (1983). The positional coding system in the early eye rudiment of Xenopus laevis, and its modification after grafting operations. J. Embryol. exp. Morph. 77, $53-71$.

Currie, J. \& Cowan, W. M. (1975). The development of the retinotectal projection in Rana pipiens. Devl Biol. 46, 453-464.

EASTER, S. S. (1983). Postnatal neurogenesis and changing connections. Trends in Neuroscience 6, 53-56.

EASTER, S. S. \& STUERMER, C. A. O. (1984). An evaluation of the hypothesis of shifting terminals in goldfish optic tectum. J. Neurosci. 4, 1052-1063.

FraSer, S. E. (1980a). Light-pipe mapping of the Xenopus retinotectal projection. J. Physiol., Lond. 305, 113p.

FrASER, S. E. (1980b). A differential adhesion approach to the patterning of nerve connections. Devl Biol. 79, 453-464.

FRASER, S. E. (1983a). Fiber optic mapping of the Xenopus visual system: Shift in the retinotectal projection during development. Devl Biol. 95, 505-511.

Fraser, S. E. (1983b). Plasticity in the retinotectal projection during normal development: Sliding connections in Rana. Soc. Neurosci. Abs. 9, 760.

FraSER, S. E. (1985). Cell interactions involved in neuronal patterning: An experimental and theoretical approach. In Molecular Bases of Neural Development (ed. G. M. Edelman, W. E. Gall \& W. M. Cowan), pp. 481-507. New York: Wiley.

FrASER, S. E. \& HUNT, R. K. (1980a). Retinotectal specificity: Models and experiments in search of a mapping function. A. Rev. Neurosci. 3, 319-352.

Fraser, S. E. \& Hunt, R. K. (1980b). Retinotectal plasticity in Xenopus: Anomalous ipsilateral projection following late larval eye removal. Devl Biol. 79, 444-452.

Fraser, S. E. \& O'RourKe, N. A. (1985). Cell dynamics in neural maps: Specificity and dynamics in retinotectal map formation. In Molecular Determinants of Animal Form (ed. G. M. Edelman). New York: A. R. Liss.

Gaze, R. M., Chung, S.-H. \& Keating, M. J. (1972). Development of the retinotectal projection in Xenopus. Nature New Biology 236, 133-135.

Gaze, R. M., Keating, M. J. \& Chung, S.-H. (1974). The evolution of the retinotectal map during development in Xenopus. Proc. R. Soc. B 185, 301-330.

Gaze, R. M., Keating, M. J., Ostberg, A. \& Chung, S.-H. (1979). The relationship between retinal and tectal growth in larval Xenopus. Implications for the development of the retinotectal projection. J. Embryol. exp. Morph. 53, 103-143.

Holt, C. (1984). Does timing of axon outgrowth influence initial retinotectal topography in Xenopus? J. Neurosci. 4, 1130-1152.

Holt, C. \& Harris, W. A. (1983). Order in the initial retinotectal map in Xenopus: A new technique for labelling growing nerve fibers. Nature, Lond. 301, 150-152.

Humason, G. L. (1979). Animal Tissue Techniques, 4th edn. San Francisco: Freeman.

JACOBSON, M. (1976). Histogenesis of the retina in the clawed frog with implications for the pattern of development of retinotectal connections. Brain Res. 103, 541-545. 
JACOBSON, M. (1977). Mapping the developing retinotectal projection in frog tadpoles by a double label autoradiographic technique. Brain Res. 127, 55-67.

MEYER, R. L. (1978). Evidence from thymidine labeling for continuing growth of retina and tectum in juvenile goldfish. Expl Neurol. 59, 99-111.

MEYER, R. L. (1982). Ordering of retinotectal connections: a multivariate operational analysis. Curr. Top. devl Biol. 17, 101-145.

O'Rourke, N. A. \& Fraser, S. E. (1986). Dynamic aspects of retinotectal map formation revealed by a vital-dye fiber-tracing technique. Devl Biol. (in press).

Reh, T. A. \& Constantine-Paton, M. (1984). Retinal ganglion cell terminals change their projection sites during larval development of Rana pipiens. J. Neurosci. 4, 442-457.

ScotT, T. M. \& LAZAR, G. (1976). An investigation into the hypothesis of shifting neuronal relationships during development. J. Anat. 121, 485-496.

Straznicky, C. \& GAZE, R. M. (1971). The growth of the retina in Xenopus laevis: An autoradiographic study. J. Embryol. exp. Morph. 26, 67-79.

Straznicky, C. \& GAZE, R. M. (1972). The development of the tectum in Xenopus laevis: An autoradiographic study. J. Embryol. exp. Morph. 28, 87-115.

VAN EsSEN, D. C. (1982). Neuromuscular synapse elimination. In Neuronal Development (ed. N. Spitzer). New York: Plenum Press.

Von Der Malsburg, C. \& Willshaw, D. J. (1977). How to label nerve cells so that they can interconnect in an orderly fashion. Proc. natn. Acad. Sci. U.S.A. 74, 5176-5178.

WhiteLAw, V. A. \& CowAN, J. D. (1982). Specificity and plasticity of retinotectal connections: A computational model. J. Neurosci. 1, 1369-1387. 


\section{.}

